Pediat. Res. 7: 818-825 (1973)

Amino acids hydroxyproline iminoglycinuria kidney proline

\title{
Metabolism and Uptake of L-Proline by Human Kidney Cortex
}

\author{
P. Holtzapple, ${ }^{[38]}$ M. Genel, C. Rea, and S. Segal \\ Departments of Pediatrics and Medicine, University of Pennsylvania School of Medicine, and the Children's Hospital of \\ Philadelphia, Philadelphia, Pennsylvania, USA
}

\begin{abstract}
Extract
L-Proline transport and metabolism have been investigated in normal adult human kidney cortical slices. The uptake of proline from buffers containing both high (10 $\mathrm{mm})$ and low $(0.23 \mathrm{~mm}){ }^{14} \mathrm{C}$-proline concentrations is intimately related to the extent of intracellular proline metabolism. The accumulation of radioactivity from both the 10 and $0.23 \mathrm{~mm}$ proline media was against high radioactivity gradients, with distribution ratios of 18 and 3, respectively. Recovered proline from the intracellular fluid (ICF) accounted for less than $12 \%$ of the intracellular radioactivity in the tissue extracts. Glutamic acid accounted for greater than $75 \%$ of the intracellular form of the soluble radioactivity in tissue extracts. Total oxidation to ${ }^{14} \mathrm{CO}_{2}$ from both proline concentrations accounted for more than $50 \%$ of the total proline taken up by the slices.

Kinetic analysis of the entry process suggested the existence of two saturable systems: one operative at low or physiologic proline concentrations (apparent $K_{m} 2 \mathrm{~mm}$ ) with a low capacity $\left(V_{\max } 40 \mu \mathrm{M} \cdot \mathrm{ml} \mathrm{ICF}-1.30 \mathrm{~min}^{-1}\right)$ and shared with neutral amino acids, and a second with an affinity to 10-fold less (apparent $K_{m} 17 \mathrm{~mm}$ ) with a high capacity $\left(V_{\max } 160 \mu \mathrm{M} \cdot \mathrm{ml} \mathrm{ICF}-1.30 \mathrm{~min}^{-1}\right)$ and unshared by the neutral amino acids. Separation of the influence of metabolism from the analysis of the transport systems by the use of proline analogues showed that thioproline inhibited proline uptake by $80 \%$, primarily by reducing the conversion of proline to glutamic acid, whereas 3,4 dehydroproline did not affect the conversion of proline to glutamic acid but principally appeared to alter the affinity of the transport system for proline.
\end{abstract}

\section{Speculation}

These studies suggest that changes in the rate of proline metabolism in the human kidney may alter the rate of tubular reabsorption, thus controlling renal proline excretion. It is possible that renal iminoglycinuric syndromes may not only be secondary to membrane transport disorders but may result from localized metabolic defects in the tubule cells.

\section{Introduction}

In humans, excessive excretion of the iminoacids-proline and hydroxyproline-and glycine is found in certain clinical situations, either as an isolated benign aminoaciduria or associated with other systemic findings. Hyperexcretion of iminoacids and glycine is pres- ent during the early postnatal period in humans and gradually diminishes by the 6th month of life as the net tubular reabsorption of glycine and the iminoacids increases. Delayed postnatal maturation of the iminoacid and glycine transport system in the renal tubule appears to be responsible for this benign finding $[3,25]$. 
Renal iminoglycinuria with normal proline metabolism and normal proline plasma concentrations which persists beyond the immediate postnatal period is ascribed to selective genetically determined iminoglycine transport defects in the renal tubule [13, 22]. In vivo proline infusion studies in man suggest distinct membrane transport systems for proline and glycine with differing degrees of mutual interaction and specificity $[16,17]$. According to these clinical studies, the membrane system with a high affinity for proline at physiologic concentrations has a low transport capacity, excludes glycine, and is saturated at normal plasma levels of proline. The shared glycine-iminoacid system has a low affinity for proline but a high capacity and is the deleted system in homozygotes with benign iminoglycinuria.

In contrast to these membrane transport defects, a familial hyperprolinemia syndrome which may be associated with mental retardation and renal malformations has been described $[5,15,19,20]$. Deficiency of either proline oxidase or $\Delta^{\prime}$-pyrroline-5-carboxylic acid dehydrogenase results in hyperprolinemia. The iminoglycinuria is ascribed to the excessive filtered load of proline and competition with glycine and hydroxyproline for the mutually shared iminoglycine transport system.

Inasmuch as the only data of proline handling by the human kidney have come from in vivo tubular reabsorption studies $[16,17]$, we have investigated proline transport and metabolism in human renal cortical slices in a series of in vitro experiments. The results of these studies form the basis of this report.

\section{Methods}

Kidneys were obtained from nine adult patients undergoing nephrectomy for either localized intrarenal or extrarenal pathology. Disease-free cortical areas (as determined by histologic evaluation) of the kidneys were used for preparation of the slices. The techniques for determining amino acid uptake in human kidney cortical slices were similar to those described by Fox et al. [7]. Slices weighing 4-8 $\mathrm{mg}$ were prepared with a Stadie-Riggs microtome. Each slice was incubated in 2 $\mathrm{ml}$ Krebs-Ringer bicarbonate buffer ( $\mathrm{pH} 7.4$ ) at $37^{\circ}$ in a metabolic shaker under an atmosphere of $95 \%$ $\mathrm{O}_{2}-5 \% \mathrm{CO}_{2}$ with $\mu \mathrm{Ci} \mathrm{L}-\mathrm{U}_{-14}{ }^{14} \mathrm{C}-$ proline, specific activity $219 \mathrm{mCi} / \mathrm{mm}$ [26], and the appropriate amounts of carrier L-proline [27]. At the end of the incubation the slices were rinsed rapidly in physiologic saline, blotted on filter paper, weighed, and the soluble radioactivity in the slice was extracted into $1 \mathrm{ml}$ water by heating in a boiling water bath for $6 \mathrm{~min}$. Aliquots $(0.2 \mathrm{ml})$ of the tissue extract and the media were added to scintillation vials with $10 \mathrm{ml}$ toluene-ethanol (72/28) which contained 3\% Liquifluor [26] and counted at 90\% efficiency in a Packard model 3003 Tri-Carb scintillation spectrometer [28].

Tissue water, expressed as the percentage of the total tissue weight, was determined for each surgical specimen by the difference in weight of 3 slices after blotting and after drying in vacuo at $105^{\circ}$ for $24 \mathrm{hr}$. Extracellular fluid space (ECF) estimation for each surgical specimen was determined by incubation with 0.5 $\mu \mathrm{Ci}$ inulin-14 ${ }^{14}$-carboxyl, specific activity $3.23 \mathrm{mCi} / \mathrm{g}$ $[12,26]$.

In selected experiments ${ }^{14} \mathrm{CO}_{2}$ production was determined by trapping the evolved carbon dioxide in the flasks fitted with center wells. Slices were weighed before incubation. Injection of $0.3 \mathrm{ml} 6 \mathrm{~N}$ sulfuric acid through the serum stopper flask cap ended the incubation. The liberated ${ }^{14} \mathrm{CO}_{2}$ was trapped in the center well after injecting $1.0 \mathrm{ml} 1 \mathrm{M}$ Hyamine into the well. After equilibration for $45 \mathrm{~min}$ by shaking at room temperature, the well was emptied into a counting vial, rinsed three times with scintillator, and counted [28].

In other experiments the radioactive metabolites in the tissue extract and media were assayed by descending paper chromatography. Aliquots of the extracts containing at least $1,200 \mathrm{cpm}$ of radioactivity were applied on Whatman no. 1 paper [29]; 90-95\% recovery of the applied radioactivity was achieved. Twenty micrograms of proline, ornithine, glutamic acid, and $\gamma^{-}$ aminobutyric acid were run as standards [27]. After development, $1-\mathrm{cm}$ segments of the papers were cut, added to scintillation counting vials, wetted with $3 \mathrm{ml}$ scintillator, and counted [28].

Intracellular proline concentrations were determined in three surgical specimens by homogenization of at least $100 \mathrm{mg}$ tissues in 5 volumes $3 \%$ sulfosalicylic acid followed by ion exchange chromatography [30]. Trapped extracellular proline was accounted for by assuming an extracellular proline concentration of $0.23 \mathrm{~mm}$, similar to human plasma levels [4, 14, 21].

\section{Calculations}

The uptake of proline is expressed as the radioactive distribution ratio, i.e., the ratio of counts per minute per milliliter of ICF to counts per milliliter of media, calculated from the soluble radioactivity in the tissue extract [7]. A chemical distribution ratio for proline was calculated from the percentage of proline in the 


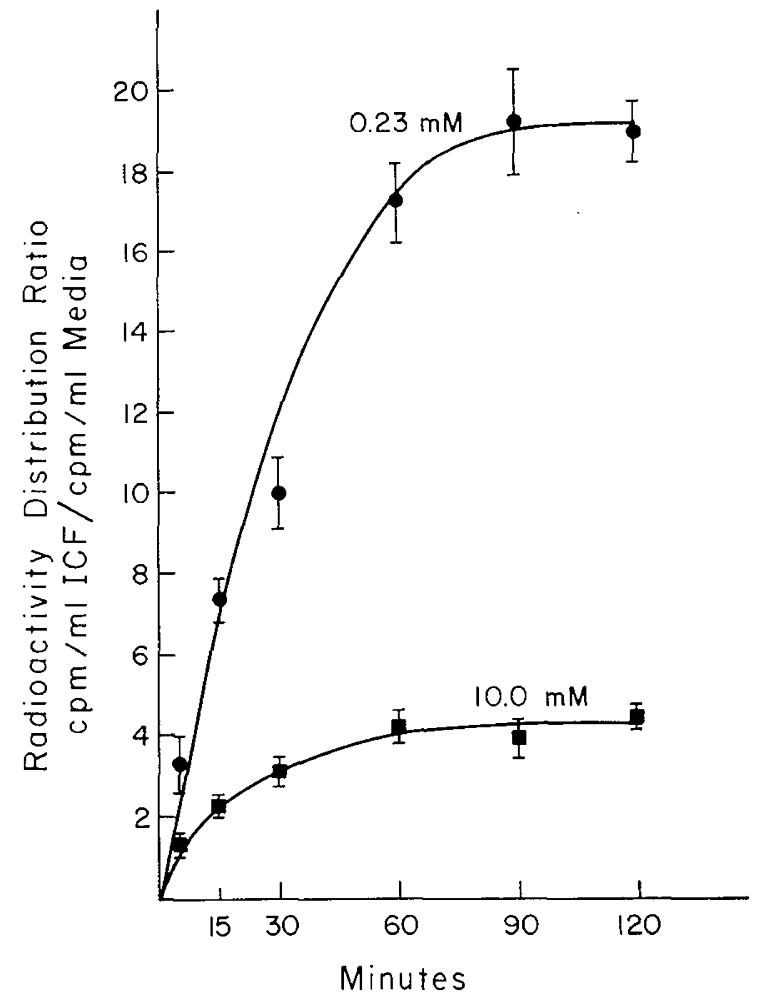

Fig. 1. Time curve of isotopic proline uptake in human kidney slices from $10 \mathrm{~mm}$ and $0.23 \mathrm{~mm}$ proline concentrations. The symbols represent the mean uptake in five different specimens incubated in duplicate flasks. The brackets represent the SE of the mean uptake. ICF: intracellular fluid.

Table 1. Intracellular ${ }^{14} \mathrm{C}$-containing compounds after incubation of human kidney cortex slices with ${ }^{14} \mathrm{C}$-proline

\begin{tabular}{cccc}
\hline Specimen $^{1}$ & $\begin{array}{c}\text { Distribution } \\
\text { ratio }\end{array}$ & $\begin{array}{c}\text { Proline, } \\
\%\end{array}$ & $\begin{array}{c}\text { Glutamic acid, } \\
\%\end{array}$ \\
\hline$T$ & 11.52 & 12 & 77 \\
$G$ & 7.92 & 0 & 86 \\
$H$ & 12.11 & 2 & 98 \\
$M$ & 8.02 & 0 & 94 \\
\hline
\end{tabular}

${ }^{1}$ Cortical slices were incubated with $0.23 \mathrm{~mm}$ proline for $30 \mathrm{~min}$ as described in Methods.

2 The distribution ratio is the ratio of counts per minutes per milliliter of intracellular fluid per counts per minute per milliliter of media.

tissue extract as determined from the chromatography. This ratio has been corrected for the radioactive proline trapped in the ECF [18]. The calculation is as follows: the expected proline radioactivity in ECF equals the total counts per minute on the chromatography paper $\times$ the fraction of the total tissue radioactivity in the ECF. The fraction of the total tissue radioactivity in $\mathrm{ECF}=[($ volume of $\mathrm{ECF}) /($ volume of
$\mathrm{ECF}+$ volume of ICF $\times$ distribution ratio)] [18]. In the substrate concentration studies, total entry into the slices was determined from the radioactivity in the tissue extract at steady state conditions [23]. The radioactivity which evolved as ${ }^{14} \mathrm{CO}_{2}$ was added to the soluble radioactivity remaining in the slice as described by Baerlocher et al. [1].

\section{Results}

\section{Cellular Uptake of Proline}

Intracellular proline concentrations in cortical tissue from three patients were determined before incubation. Proline concentrations of $0.86,0.74$, and $0.18 \mathrm{~mm}$ were found. By assuming a mean plasma concentration of $0.23 \mathrm{~mm}[4,14,21]$, an intracellular to extracellular gradient for proline exists in the human kidney. Subsequently, experiments were performed with 10 and 0.23 mM proline concentrations.

The uptake of proline with time into kidney slices is depicted in Figure 1. Rapid uptake of proline at the low concentration occurred; maximal radioactivity gradients of 19 at steady state were obtained after a 90-min incubation. Steady state conditions at the high media concentration of proline were reached by 30 min of incubation with radioactivity gradients of 4 . In $\mathrm{pH}$ dependence studies maximal uptake from both media concentrations was seen at a $\mathrm{pH}$ of 7.4.

\section{Intracellular Metabolites of $L$-Proline}

The intracellular form of the accumulated radioactivity was ascertained in slices from 4 different kidneys (Table I). After a $30-\mathrm{min}$ incubation with $0.23 \mathrm{~mm}$ proline little or none of the intracellular radioactivity was recovered as chemical proline. The major soluble metabolite in the intracellular space was glutamic acid, comprising $77,86,94$, and $98 \%$, respectively. The remainder of the recovered radioactivity on the chromatography paper migrated to an area which corresponded to the standards for ornithine and $\gamma$-aminobutyric acid. The combined total of these latter two metabolites was always less than $10 \%$ of total intracellular forms.

At the higher media concentrations there was an increase in the proportion of the intracellular radioactivity that was represented by proline. In two specimens incubated for 30 min with $10 \mathrm{~mm}$ proline, the intracellular proline was 50 and $23 \%$, respectively, correspondingly, there was a proportional reduction in 
the percentage of the radioactivity migrating as glutamic acid, accounting for 48 and $66 \%$, respectively.

Chromatography of an aliquot of media after a 30 min incubation showed that more than $98 \%$ of the radioactivity could be recovered as proline, which indicated that there was little or no efflux of proline metabolites from the slices.

\section{Oxidation of Proline by Human Cortex and Estima- tion of Total Proline Uptake}

In addition to the tissue metabolities of the transported proline, oxidation of proline to ${ }^{14} \mathrm{CO}_{2}$ was also a significant factor in evaluation of total uptake of proline by kidney slices. Oxidation of proline by slices from one surgical specimen with respect to time is shown in Figure 2. At both the $0.23 \mathrm{~mm}$ and $10 \mathrm{~mm}$ media concentrations there is an initial lag phase during which a slow progressive increase in carbon dioxide production is noted. After $30 \mathrm{~min}$ an accelerated phase is evident; production levels off after $90 \mathrm{~min}$ of incubation.

In Figures 3 and 4 the estimate of total cellular uptake of proline in terms of both the amount oxidized and the amount of intracellular metabolites in one specimen is depicted. From the $0.23 \mathrm{~mm}$ media concentration, chemical proline at $5 \mathrm{~min}$ represents

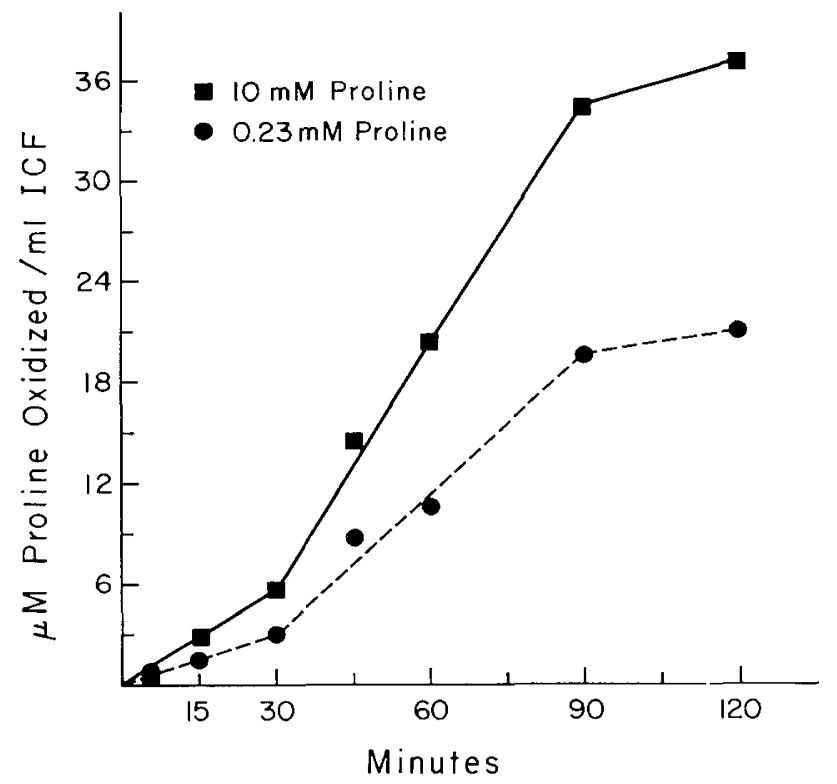

Fig. 2. Oxidation of radioactive proline to ${ }^{14} \mathrm{CO}_{2}$ from media concentrations of $0.23 \mathrm{~mm}$ and $10 \mathrm{~mm}$ with time. Oxidation is expressed as micromolar concentration of proline oxidized per milliliter of intracellular fluid $(I C F)$ by assuming complete oxidation of the proline molecule.

\section{$0.23 \mathrm{mM}$ L-PROLINE}

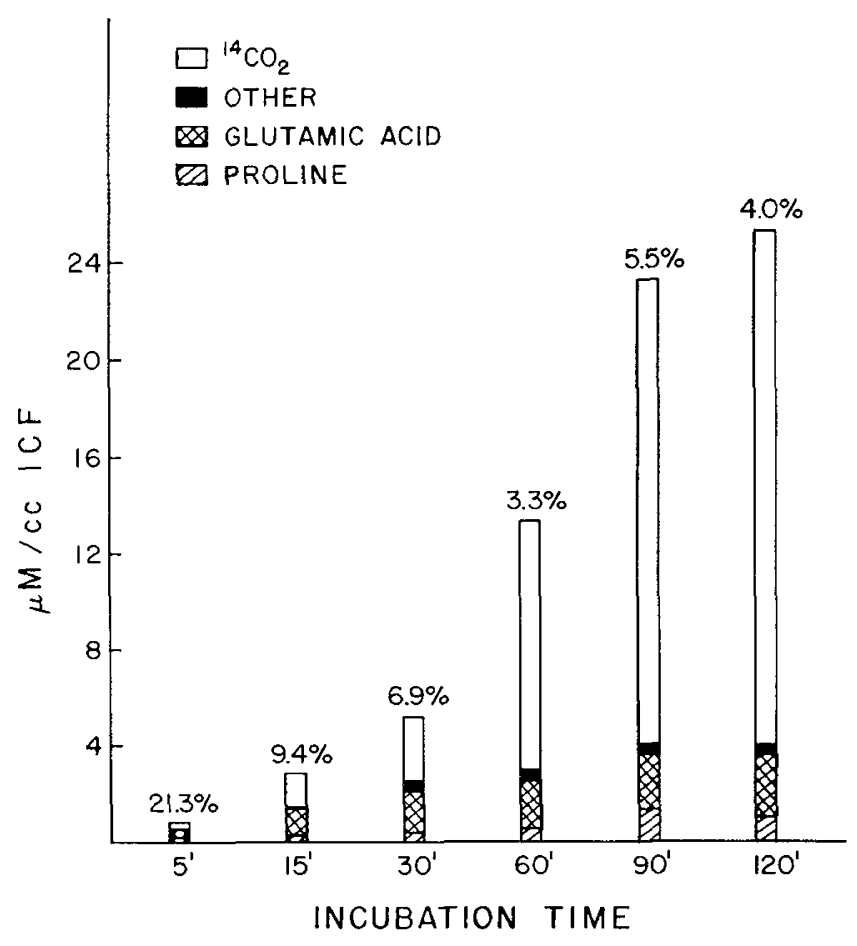

Fig. 3. The metabolic fate of proline taken up by human kidney slices from $0.23 \mathrm{mM}$ proline after varying incubation times. The data are expressed as micromolar concentration of proline taken up per each milliliter of intracellular fluid $(I C F)$. The numbers at the top of the bars represent the percentage of the total intracellular radioactivity which is proline.

only $21 \%$ of the total amount of transported proline. As the oxidative rate increases after the first $30 \mathrm{~min}$, chemical proline represents less than $5 \%$ after $30 \mathrm{~min}$ of incubation. At this media concentration, a true chemical gradient for proline could not be achieved. With uptake of proline from the $10 \mathrm{~mm}$ media concentration, a true chemical gradient of approximately 2.0 was achieved after a 60-min incubation, but still over $60 \%$ of the transported proline had been metabolized by $60 \mathrm{~min}$.

\section{Substrate Concentration Studies}

The uptake of proline by the human cortex cells appears to be concentration dependent. Analysis of the process suggests two modes of uptake as shown in Figure 5 which is an Eadie-Hofstee plot of a study in one human kidney (specimen $K$ ). The derived $K_{m}$ and $V_{\max }$ from the data shown in the plot and from a similar 
$10.0 \mathrm{mM}$ L-PROLINE

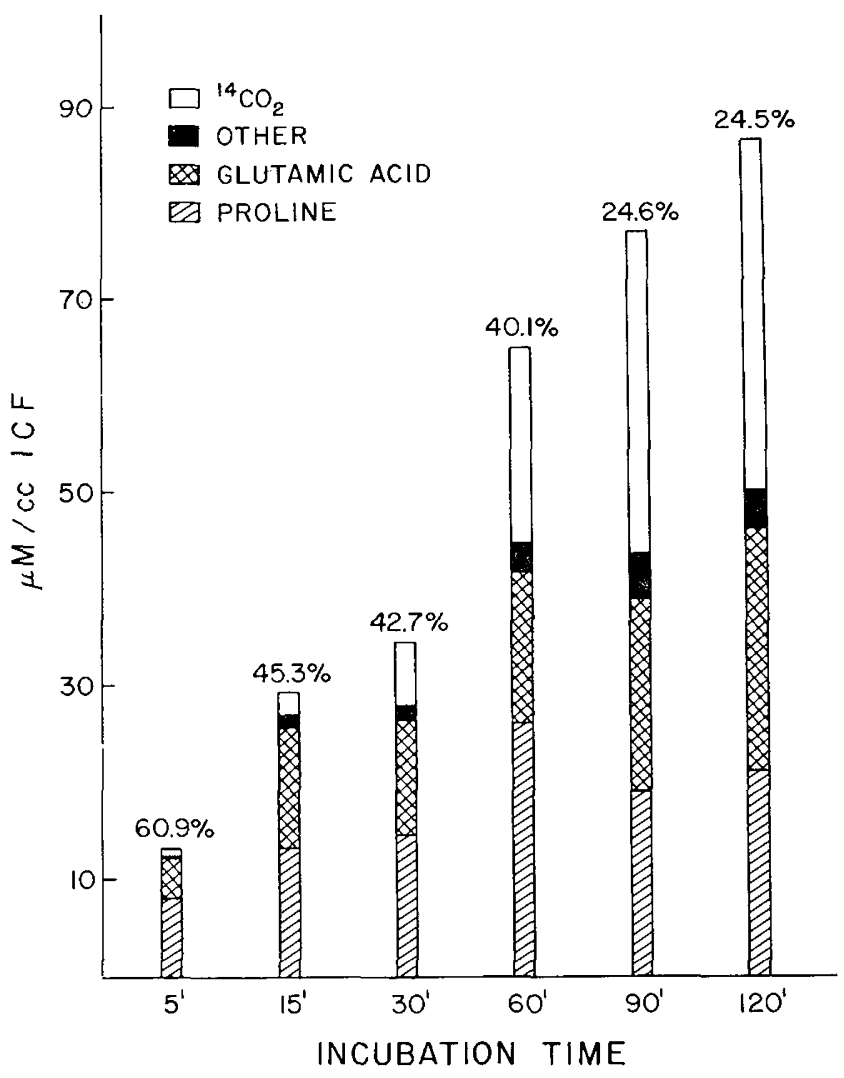

Fig. 4. The metabolic fate of proline taken up by human kidney slices from $10 \mathrm{~mm}$ proline after variation of incubation times. The data are expressed as micromolar concentration of proline taken up per each milliliter of intracellular fluid $(I C F)$. The numbers at the top of the bars represent the percentage of the total intracellular radioactivity which is proline.

study in another specimen (specimen $T$ ) is seen in the inset of the figure. On the basis of cellular content of proline and its soluble metabolites one mode of entry has a high affinity (apparent $K_{m}$ values of 0.7 and 0.9 $\mathrm{mm} /$ liter) but a low capacity for proline transport (maximal velocity of 7.8 and $13 \mu \mathrm{M} / \mathrm{ml} / 30 \mathrm{~min}$ ). The other mode has a low affinity (apparent $K_{m}$ values of 23 and $30 \mathrm{~mm} /$ liter) but a large capacity for proline entry ( $V_{\max }$ of 53 and $\left.75 \mu \mathrm{M} / \mathrm{ml} / 30 \mathrm{~min}\right)$. In accounting for all of the transport in proline by adding the amount of proline oxidized to ${ }^{14} \mathrm{CO}_{2}$ at the various substrate concentrations to the ${ }^{14} \mathrm{C}$ remaining in the tissue extract, the apparent affinity of proline for the saturable sites does not change; however, the capacity as indicated by the maximal velocity of uptake increases 2-3-fold in both the "high" and "low" $K_{m}$ systems.
Effects of Inhibitors and Sodium or Oxygen Deprivation

The effects of other amino acids and deprivation of sodium and oxygen on proline uptake and metabolism are shown in Table II. Proline uptake from $0.065 \mathrm{~mm}$ media concentration is inhibited by $\alpha$-aminoisobutyric acid. Both $\alpha$-aminoisobutyric acid and valine produce a $50 \%$ reduction in the accumulation of radioactivity.

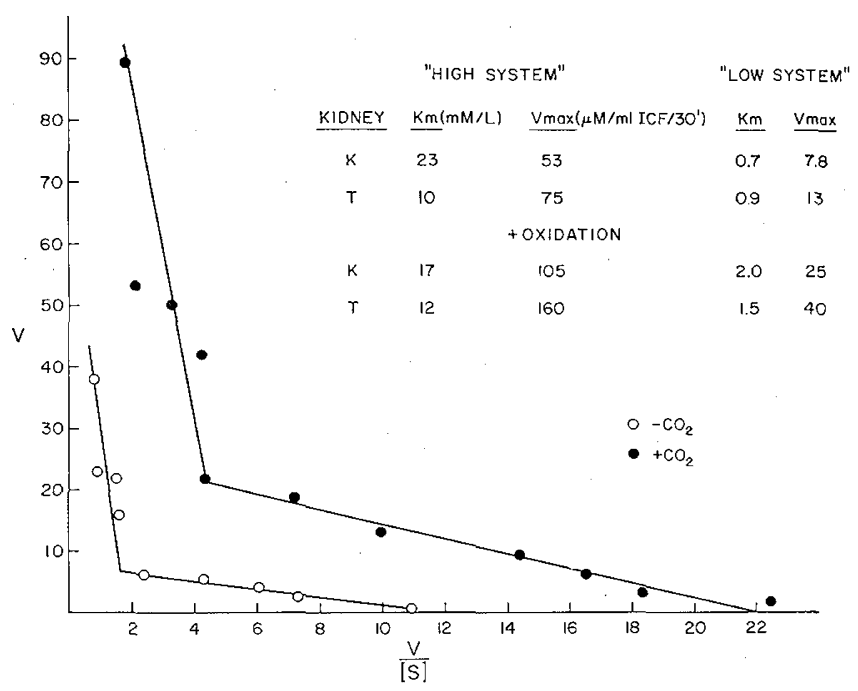

Fig. 5. Eadie-Hofstee plot of concentration-dependent proline uptake in human kidney cortex (specimen $K$ ). Each point is the mean value obtained from 5 -mg slices incubated for $30 \mathrm{~min}$ in triplicate. The data is expressed without $(O)$ and with $(\bullet)$ the amount of oxidation at each substrate concentration. The apparent $K_{m}$ values and $V_{\max }$ valucs are shown in the inset.

Table II. Inhibition of proline uptake ${ }^{1}$

\begin{tabular}{lccccccc}
\hline Specimen & Control & $\mathrm{AIB}^{2}$ & Valine & $\begin{array}{c}\text { Thio- } \\
\text { proline }\end{array}$ & $\begin{array}{c}\text { 3,4-De- } \\
\text { hydro- } \\
\text { proline }\end{array}$ & $\begin{array}{c}\mathrm{Na}^{+}- \\
\text {Free }^{3}\end{array}$ & $\begin{array}{c}\text { Anaero- } \\
\text { biosis }\end{array}$ \\
\hline $\begin{array}{l}\text { Media, } \\
\quad\end{array}$ & & & & & & & \\
$\quad$ mM & & & & & & & \\
$G$ & $11.62^{4}$ & 4.02 & 5.25 & 2.41 & & 2.86 & 4.15 \\
$S$ & 13.71 & 6.07 & 6.73 & & & 2.24 & 1.89 \\
$H$ & 12.11 & & 7.03 & 1.42 & & & \\
$M$ & 8.02 & & & 1.83 & 2.61 & & \\
Media, 10 & & & & & & & \\
$\quad$ mM & & & & & & & \\
$G$ & 4.24 & 3.22 & 2.62 & 0.63 & & 2.68 & 1.99 \\
$S$ & 4.61 & 2.83 & 3.28 & & & 2.23 & 3.05 \\
\hline
\end{tabular}

I The inhibitor concentrations were $25 \mathrm{~mm}$ for $0.065 \mathrm{~mm}$ proline and $50 \mathrm{~mm}$ for the $10 \mathrm{~mm}$ proline concentration.

2 AIB : $\alpha$-aminoisobutyric acid.

${ }^{3}$ Tris was substituted for sodium in the preparation of the buffer.

${ }^{4}$ All values represent the radioactive distribution ratios at 30 min of incubation. 
The proportions, however, of the intracellular metabolities did not change. Glutamic acid accounted for more than $90 \%$ and proline only $5 \%$ of the intracellular accumulation in two specimens in which chromatography of the tissue extract was accomplished. The neutral amino acids has less, if any, effect on proline uptake from the $10 \mathrm{~mm}$ media concentration.

The inhibition of proline uptake by thioproline [31] (thiozolidine-4-carboxylic acid), a metabolizable proline analogue, and 3,4-dehydroproline [32] was greater than that of the neutral amino acids (Table II). Although the inhibitory effect of these two agents on proline uptake is similar, the intracellular forms of radioactivity are different. In two specimens (specimens $H$ and $M$ ), chemical proline accounted for more than $60 \%$ of the intracellular radioactivity in slices incubated with $25 \mathrm{~mm}$ thioproline. A component which migrated in the $\gamma$-aminobutyric acid area of the chromatogram accounted for 22 and $30 \%$ of the remaining intracellular radioactivity. In contrast, chromatography of the extract of specimen $M$ incubated with $25 \mathrm{~mm}$ 3,4-dehydroproline was not different from that of noninhibited control slices. Chemical proline and glutamic acid accounted for 15 and $84 \%$ of the intracellular radioactivity, respectively. Thus, it appears that the mode of inhibition of proline uptake by these two proline analogues is different; thioproline has an effect on the intracellular metabolism of proline as well as on uptake, while the 3,4-dehydroproline effect appears to be inhibitory to proline uptake at the plasma level only.

Both complete replacement of the media sodium by equimolar Tris or anaerobic incubation cause an inhibition of proline uptake (Tables II and III). At the

Table III. Effect of sodium and oxygen deprivation on in tracellular forms ${ }^{1}$

\begin{tabular}{crrr} 
Conditions & D.R. ${ }^{2}$ & $\begin{array}{c}\text { Proline, } \\
\%\end{array}$ & $\begin{array}{c}\text { Glutamic } \\
\text { acid, } \\
\%\end{array}$ \\
\hline Media, $0.065 \mathrm{~mm}$ & & & \\
Control & 11.62 & 19 & 69 \\
Sodium free & 2.86 & 0 & 88 \\
Anaerobiosis & 4.15 & 50 & 32 \\
Media, 10 mM & & & \\
Control & 3.24 & 24 & 58 \\
Sodium free & 2.68 & 31 & 42 \\
Anaerobiosis & 1.99 & 40 & 27
\end{tabular}

1 A 5 -mg slice was incubated in $2 \mathrm{ml} \mathrm{Krebs-Ringer-bicarbonate}$ buffer ( $\mathrm{pH} 7.1$ ) for $30 \mathrm{~min}$ with $0.2 \mu \mathrm{Ci}{ }^{14} \mathrm{C}$-proline. Sodium-free buffer was prepared with equimolar Tris. Anaerobic flasks were gassed with $\mathrm{N}_{2} / \mathrm{CO}_{2}(95 / 5)$ for $45 \mathrm{sec}$ and sealed.

${ }^{2}$ D.R.: radioactive distribution ratio. lower media concentration, the effect of the sodiumfree media not only reduced proline uptake by $80 \%$ but also reduced the level of intracellular proline from $19 \%$ in the control slices to $0 \%$. Under conditions of anaerobiosis uptake was impaired to the same extent as seen with sodium-free conditions; however, chemical proline in the extract accounted for $50 \%$ of the accumulated intracellular radioactivity at $30 \mathrm{~min}$ of incubation. The inhibition of proline uptake from $10 \mathrm{~mm}$ media concentration was less for both sodium-free and anaerobic conditions. However, under both conditions the proportion of intracellular proline increased from the control uptake levels.

\section{Discussion}

Proline, a nonessential amino acid, is metabolized by mammalian tissues to glutamic acid in a two-step sequence. It is first oxidized by a mitochondrial enzyme, proline oxidase, to $\Delta^{\prime}$-pyrroline-5-carboxylic acid [9]. Spontaneous conversion of $\Delta^{\prime}$-pyrroline-5-carboxylic acid to glutamic- $\gamma$-semialdehyde can occur. The $\Delta^{\prime}$-pyrroline-5-carboxylic acid can be dehydrogenated by $\Delta^{\prime}$ pyrroline-5-carboxylic acid dehydrogenase also present in mitochondria. Both of these enzymes have been found in rat and bovine liver and in human liver, kidney, and brain [5]. The resultant glutamic acid is further metabolized by several reactions, the most important of which is transamination to $\alpha$-ketoglutarate. Decarboxylation to $\gamma$-aminobutyric acid by glutamic acid dehydrogenase, an enzyme whose relative activity in the rat kidney is greater than that in the brain, has recently been described in the human kidney [24].

The results of our studies showing extensive proline metabolism in human renal cortical slices support the concept that the human kidney may be an important site for the regulation of proline homeostasis. This was first suggested by Felig et al. [6] in studies demonstrating consistent renal extraction of proline in the postabsorptive and fasting conditions. In both states renal arterial-venous differences were significantly greater than differences across the hepatic bed [6]. Although our data with the kidney slice do not allow estimations of the relative importance of the various pathways of glutamic acid clegradation, complete oxidation of proline appears to be the major fate of the transported proline. We assume that the tubule cells which constitute the majority of the cell types in a cortical slice are responsible for this metabolism of proline. However, MacKenzie and Scriver [10] found that isolated rat glomeruli are able to convert proline to glutamic acid 
and carbon dioxide. Therefore, some of the metabolic products of proline conversion could come from glomerular metabolism in the cortical slice.

In our studies and in the rat slice studies reported by Baerlocher et al. [1, 2], the rapidity of the proline degradation raises some questions as to the nature of the intracellular proline gradients. Our data suggest that at the physiologic levels a true proline gradient calculated from the percentage of intracellular proline present after incubation was only slightly more than unity and could represent intracellular accumulation by an equilibrating or facilitated diffusion system.

Because of the significant amount of proline metabolism in the cortical slices, the characterization of the membrane transport system is difficult. Time- and concentration-dependent studies suggest that a steady state of entry is achieved after $30 \mathrm{~min}$ of incubation and that the transport system is saturable. Two modes of entry with differing affinities for a saturable membrane reactive site are apparently present. In these general characteristics the human transport process for proline is similar to that which exists in the rat [11] and the rabbit tubule [8]. The affinity of the saturable system operative at the low proline concentrations in human kidney is similar to that estimated for both the rat and the rabbit transport system $[8,11]$.

In studying the effects of various inhibitors on the transport system in human kidney, differences in the physiologic system are apparent. The effects of inhibitors suggest that neutral amino acids as represented by $\alpha$-aminoisobutyric acid reduce proline uptake proportionally more from physiologic concentrations than from high media concentrations. The data from our study and that of the isolated rabbit tubules system delineate a component of the low $K_{m}$ system for proline which is shared with neutral amino acids [8]. In contrast, the same system in rat cortical slices does not interact with neutral amino acids as represented by either $\alpha$-aminoisobutyric acid or alanine [11].

In an attempt to separate proline metabolic effects from influencing the cellular entry process, proline analogues were used. Thioproline is metabolized by rat liver mitochondria by the same enzyme, proline oxidase, which catalyzes the conversion of proline to glutamic- $\gamma$-semialdehyde [9]. The fact that thioproline inhibited glutamic acid formation and caused an increase in cellular radioactive proline is consistent with this compound having a primary effect on proline oxidation. However, we cannot rule out the possibility that thioproline did not have an effect on the site of proline transport in the cell membrane. DL-3,4-Dehy- droproline did not affect the intracellular metabolism of accumulated proline. The inhibitory effect was as great as that of thioproline on the radioactive accumulation of proline. This suggests that the 3,4 dehydroproline was active principally at the membrane carrier site for proline and exerted its inhibitory effect on proline uptake by this interaction.

The influence of metabolism on the transmembrane movement of proline in the human kidney raises some questions concerning the etiology of prolinuria in both the familial hyperprolinemic syndromes with known enzymatic defects $[5,15,19,20]$ and the hyperprolinuria renal tubule syndromes $[13,16,17,22]$. The degree of prolinuria in the former syndromes may be related not only to an increased filtered load of proline but also to defects in the tubular metabolism of proline, resulting in impairment of tubular reabsorption of the filtered proline load. The hyperiminoglycinuric phenotypes, presumably disorders to specific membrane transport carriers, may result from alterations at the renal level in the control of proline metabolism. A local change in the kidney resulting in a reduction of proline oxidation, usually rapid, could be responsible for an increase in the excretion rate of proline. This hypothesis remains to be evaluated.

\section{Summary}

Studies of L-proline uptake by human kidney cortical slices indicated the existence of two separate transport systems with differing affinity and capacity for proline. Oxidation and conversion to glutamic acid of the accumulated intracellular proline occurred so rapidly that a true gradient for proline at physiologic concentrations did not exist. Inhibition of proline metabolism either by anaerobiosis or by thioproline resulted in a significant reduction in proline uptake by the slices. The data suggest that changes in renal metabolism of proline may influence physiologic function of tubular transport systems.

\section{References and Notes}

1. Baerlocher, K. E., Scriver, C. R., and Mohyuddin, F.: The ontogeny of amino acid transport in rat kidney. I. Effect of distribution ratios and intracellular metabolism of proline and glycine. Biochim. Biophys. Acta, 249: 353 (1971).

2. Baerlocher, K., Scriver, C., and Mohyuddin, F.: The ontogeny of amino acid transport in rat kidney. II. Kinetics of uptake and effect of anoxia. Biochim. Biophys. Acta, 249: 364 (1971).

3. BRodehl, J., AND Gellissen, K.: Endogenous renal transport of free amino acids in infancy and childhood. Pediatrics, 42: 395 (1968). 
4. Dickinson, J. C., Rosenblum, H., and Hamilton, P. B.: Ion exchange chromatography of the free amino acids in the plasma of the newborn infant. Pediatrics, 36: 2 (1965).

5. Efron, M. L.: Familial hyperprolinemia: Report of a second case, associated with congenital renal malformations, hereditary hematuria and mild mental retardation with demonstration of an enzyme defect. New Engl. J. Med., 272: 1243 (1965).

6. Felig, P., Owen, O. E., Warren, J., and Cahill, G. F., Jr.: Amino acid metabolism during prolonged starvation. J. Clin. Invest., 48: 584 (1969).

7. Fox, M., Thier, S., Rosenberg, L., Kiser, W., and Segal, S.: Evidence against a single renal transport defect in cystinuria. New Engl. J. Med., 270: 556 (1964).

8. Hillman, R. E., and Rosenberg, L. E.: Amino acid transport by isolated mammalian renal tubules. II. Transport systems for L-proline. J. Biol. Chem., 244: 4494 (1969).

9. Johnson, A. B., AND STRECKER, H. J.: The interconversion of glutamic acid and proline. IV. The oxidation of proline by rat liver mitochondria. J. Biol. Chem., 237: 1876 (1962).

10. MacKenzie, S., and Scriver, C. R.: Transport of L-proline and $\alpha$-aminoisobutyric acid in the isolated rat kidney glomerulus. Biochim. Biophys. Acta, 241: 725 (1971).

11. Mohyudin, F., ANd Scriver, C. R.: Amino acid transport in mammalian kidney: Multiple systems for imino acids and glycine in rat kidney. Amer. J. Physiol., 219: 1 (1970).

12. Rosenberg, L. E., Downing, S. J., ANd SEgal, S.: Extracellular space estimation in rat kidney slices using $\mathrm{C}^{14}$ saccharides and phlorizin. Amer. J. Physiol., 202: 800 (1962).

13. Rosenberg, L. E., Durant, J. L., and Elsas, L. J., II: Familial iminoglycinuria: An inborn error of renal tubular transport. New Engl. J. Med., 278: 1407 (1968).

14. Rosenberg, L. E., ANd Scriver, C. R.: Amino acid metabolism. In: P. K. Bondy: Duncan's Diseases of Metabolism, Ed. 6 (Saunders, Philadelphia, 1969).

I5. Schaefer, I. A., SCriver, C. R., ANd EFron, M. L.: Familial hyperprolinemia, cerebral dysfunction and renal anomalies occurring in a family with hereditary nephropathy and deafness. New Engl. J. Med., 267: 51 (1962).

16. SCRIVER, C. R.: Renal tubular transport of proline, hydroxyproline and glycine. III. Genetic basis for more than one mode of transport in human kidney. J. Clin. Invest., 47: 823 (1968).

17. SCRIVER, C. R., AND Wilson, O. H.: Amino acid transport: Evidence of genetic control of two types in human kidney. Science, 155: 1428 (1967).

18. Segal, S., and Crawhall, J. C.: Transport of cysteine by human kidney cortex in vitro. Biochem. Med., 1: 141 (1967).
19. Selkoe, D. J.: Familial hyperprolinemia and mental retardation. Neurology, 19: 494 (1969).

20. Simila, S.: Hyperprolinaemia type II. Ann. Clin. Res., 2: 143 (1970).

21. Soupart, P.: Free amino acids of blood and urine in the human. In: J. T. Holden: Amino Acid Pools, p. 220 (Elsevier Publishing Company, Amsterdam, 1962).

22. Tado, K., Movikawa, T., Ando, T., Yoshida, T., and MinaGawa, A.: Prolinuria. New renal tubular defect in transport of proline and glycine. Tohoka J. Exp. Med., 87: 133 (1965).

23. Tenenhouse, A., ANd Quastel, J. H.: Amino acid accumulation in Ehrlich ascites carcinoma cells. Can. J. Biochem. Physiol., 38: 1311 (1960).

24. Whelan, D. T., Scriver, C. R., And Mohyuddin, F.: Glutamic acid decarboxylase and gamma-aminobutyric acid in mammalian kidney. Nature, 224: 916 (1969).

25. Woolf, L. I., ANd Norman, A. P.: The urinary excretion of amino acids and sugars in early infancy. J. Pediat., 50:271 (1957).

26. New England Nuclear, Boston, Mass.

27. Schwarz-Mann Research Company, New York, N. Y.

28. Packard Instrument Company, Downers Grove, Ill.

29. Fisher Scientific Company, King of Prussia, Penn.

30. Beckman-Spinco amino acid analyzer model 120C, BeckmanSpinco, Palo Alto, Calif.

31. Nutritional Biochemical Company, Cleveland, Ohio.

32. Calbiochem Corporation, San Diego, Calif.

33. The authors wish to express their gratitude to Drs. John Murphy and Harry Schoenberg for supplying the surgical specimens.

34. This work was presented in part at the Society for Pediatric Research, Atlantic City, N. J., May 1970.

35. Dr. P. Holtzapple is the recipient of United States Public Service Career Development Award no. K9-HD-70026.

36. The present address of Dr. M. Genel is: Department of Pediatrics, Yale University School of Medicine, New Haven, Conn.

37. This work was supported by a grant from the John A. Hartford Foundation and by Grant no. AM 10894 from the National Institutes of Health.

38. Requests for reprints should be addressed to: P. Holtzapple, M.D., Children's Hospital of Philadelphia, 1740 Bainbridge St., Philadelphia, Penn.

39. Accepted for publication May 22, 1973. 